\title{
Significância clínica de estafilococos coagulase-negativa isolados de recém-nascidos
}

\author{
Clinical significance of coagulase-negative staphylococci isolated from neonates
}

\author{
Maria de Lourdes R.S. Cunha ${ }^{1}$, Carlos A.M. Lopes $^{2}$, Lígia M.S.S. Rugolo ${ }^{3}$, Liciana V.A.S. Chalita ${ }^{4}$
}

\section{Resumo}

Objetivo: avaliar a significância clínica de estafilococos coagulase-negativa $(\mathrm{ECN})$ isolados de processos infecciosos em recémnascidos da unidade neonatal do Hospital das Clínicas da Faculdade de Medicina de Botucatu.

Método: as linhagens de ECN isoladas foram identificadas e classificadas em significativas e contaminantes, com base em uma série de dados clínicos e laboratoriais obtidos dos prontuários dos pacientes internados na unidade neonatal. Foram pesquisados os dados referentes a fatores perinatais de risco para infecção, evolução clínica, alterações do hemograma e/ou positividade de proteína Creativa e antibioticoterapia.

Resultados: das 117 linhagens de ECN isoladas, 60 (51,3\%) foram classificadas como significativas, e $57(48,7 \%)$ como contaminantes. Das 54 crianças com infecção por ECN, $43(79,6 \%)$ eram prematuras, e $27(50,0 \%)$ tiveram peso ao nascimento $<1.500 \mathrm{~g}$. A maioria das crianças com infecção por ECN estava submetida a dois ou mais procedimentos invasivos $(77,8 \%)$, incluindo o uso de cateter $(88,9 \%)$, nutrição parenteral $(64,8 \%)$ e ventilação mecânica $(61,1 \%)$. O S. epidermidis foi a espécie mais freqüentemente isolada $(77,8 \%)$, e mais associada com infecção $(86,7 \%)$ do que com contaminação $(68,4 \%)$. Outras espécies de ECN, incluindo duas linhagens de $S$. haemolyticus, três linhagens de $S$. lugdunensis, uma linhagem de $S$. simulans, uma de $S$. warneri e uma linhagem de $S$. xylosus também foram isoladas de crianças com evidência clínica de pneumonia, enterocolite necrosante e sepse.

Conclusão: a maioria dos recém-nascidos com infecção por ECN apresentou fatores predisponentes importantes para a instalação do processo infeccioso, incluindo o peso de nascimento $<1.500 \mathrm{~g}$, a não remoção de corpo estranho e a antibioticoterapia prévia. A identificação de espécies de ECN constitui um marcador útil de infecção, visto que o S. epidermidis foi o agente etiológico mais freqüentemente associado aos processos infecciosos.

J Pediatr (Rio J) 2002; 78 (4): 279-88: recém-nascido, infecção, estafilococos coagulase-negativa, fatores de risco.

\begin{abstract}
Objective: to evaluate the clinical significance of coagulasenegative staphylococci (CNS) isolated from newborns' infections at Neonatal Unit of Hospital das Clínicas da Faculdade de Medicina de Botucatu.

Methods: the CNS strains isolated were identified and classified as clinically significant and contaminant, based on a series of clinical and laboratory data obtained from patients who stayed in the Neonatal Unit. The following data were analyzed: risk factors for infections, clinical evolution, abnormal blood cell counts and/or Creactive protein e antibiotic therapy.

Results: among the 117 CNS strains isolated, 60 (51.3\%) were classified as significant and $57(48.7 \%)$ as contaminant. Among the 54 infants infected by CNS, $43(79.6 \%)$ presented very low birthweight $(<1,500 \mathrm{~g})$. Most of the infants infected by CNS were submitted to two or more invasive procedures $(77.8 \%)$, including use of catheter $(88.9 \%)$, parenteral nutrition $(64.8 \%)$ and mechanical ventilation (61.1\%). Staphylococcus epidermidis was the most frequently isolated species $(77.8 \%)$ and more often associated with infection (86.7\%) than with contamination (68.4\%). Other species of CNS, including two strains of $S$. haemolyticus, three strains of $S$. lugdunensis, one strain of $S$. simulans, one strain of $S$. warneri and one strain of $S$. xylosus were also isolated from infants with clinical evidence of pneumonia, necrotizing enterocolitis and sepsis

Conclusions: most newborns infected by CNS presented important risk factors for infection onset, including birthweight $<1,500 \mathrm{~g}$, foreign body presence and previous use of antibiotics. The identification of CNS species constitutes a useful marker of infection, since S. epidermidis was the species more frequently associated with infection.
\end{abstract}

J Pediatr (Rio J) 2002; 78 (4): 279-88: neonates, infection, coagulase-negative staphylococci, risk factors.

\footnotetext{
1. Professor Assistente Doutor - Dep. de Microbiologia e Imunologia - Instituto de Biociências/ UNESP-Botucatu.

2. Professor Titular - Dep. de Microbiologia e Imunologia - Instituto de Biociências/ UNESP-Botucatu

3. Professor Assistente Doutor - Dep. de Pediatria- Faculdade de Medicina/ UNESP-Botucatu.

4. Professor Assistente Doutor - Dep. de Bioestatística - Instituto de Biociências/ UNESP-Botucatu.

Fonte financiadora: FAPESP

Artigo submetido em 13.12.01, aceito em 05.06.02.
} 


\section{Introdução}

No gênero Staphylococcus, a espécie Staphylococcus aureus, coagulase-positiva e produtora de uma série de outras enzimas e toxinas, é a mais conhecida, e freqüentemente implicada na etiologia de uma série de infecções e intoxicações no homem e nos animais, enquanto que os estafilococos coagulase-negativa (ECN) têm sido considerados saprófitas ou raramente patogênicos ${ }^{1}$.

Contudo, durante a última década, considerável progresso na classificação sistemática dos estafilococos e no desenvolvimento de métodos para a identificação do gênero, espécies e subespécies, tem permitido aos clínicos se inteirarem da variedade de ECN presentes em amostras clínicas e, assim, os considerarem como agentes etiológicos de uma série de processos infecciosos ${ }^{2}$. Atualmente, são reconhecidos como microrganismos essencialmente oportunistas, que se prevalecem de inúmeras situações orgânicas para produzir graves infecções ${ }^{3}$.

Esses microrganismos apresentam elevado risco potencial de bacteremia nosocomial entre recém-nascidos de baixo peso, os quais são imunologicamente imaturos, e freqüentemente requerem procedimentos invasivos para administração de substâncias nutritivas e medicamento$\operatorname{sas}^{4,5}$. O aumento da incidência de bacteremia nosocomial por ECN em neonatos, nos últimos 20 anos, tem sido também associado ao da sobrevivência de crianças prematuras com peso menor que $1.500 \mathrm{~g}$ ao nascimento e à sua longa permanência no ambiente hospitalar ${ }^{6,7}$.

Contudo, a interpretação de hemoculturas positivas para os ECN é particularmente difícil devido ao fato desses microrganismos colonizarem a pele e as membranas mucosas como comensais, e poder contaminar as hemoculturas durante a coleta de sangue ${ }^{2}$. A esse respeito, investigadores têm usado uma variedade de critérios clínicos e laboratoriais para distinguir contaminação de bacteremia. Assim, o diagnóstico de bacteremia tem sido feito com base nos dados clínicos dos pacientes e no isolamento de microrganismos idênticos em duas ou mais hemoculturas. As culturas em que ocorre o crescimento de múltiplas linhagens ou de espécies de ECN, em associação às outras espécies de microrganismos, são classificadas como contaminantes ${ }^{2}$. Entretanto, como o volume sangüíneo é pequeno em recémnascidos prematuros com baixo peso, somente uma hemocultura é geralmente realizada para se evitar a necessidade e os riscos de transfusões devido a venopunções constantes $^{2}$. Assim, os neonatologistas têm-se apoiado em critérios clínicos e laboratoriais, tais como letargia, intolerância alimentar, distensão abdominal, deterioração da função respiratória, instabilidade da temperatura corpórea, fatores de risco perinatais e dados hematológicos, dentre outros ${ }^{8,9}$.

Os ECN podem ser facilmente diferenciados em espécies através de suas características bioquímicas ${ }^{1}$, contudo, na maioria dos laboratórios de microbiologia clínica, tal identificação não é feita de rotina. Há divergências na literatura específica sobre o significado clínico da identificação de
ECN; de acordo com os dados de alguns autores ${ }^{10}$, esse procedimento não é clinicamente significativo, embora outros pesquisadores ${ }^{11}$ acreditem que essa identificação seja importante na diferenciação entre contaminação e infecção. Segundo Archer ${ }^{12}$, a identificação dos ECN é de grande importância para a associação de certas espécies com infecções específicas, tendo em vista que alguns dados sugerem que além de S. epidermidis e S. saprophyticus, que têm sido considerados patogênicos, algumas espécies como o S. haemolyticus, S. lugdunensis e o S. schleiferi estão mais associados às infecções do que outras espécies ${ }^{13-15}$.

Embora a capacidade dos ECN de causar infecções seja bem documentada, esses microrganismos têm sido em muitos casos negligenciados quanto à sua importância clínica. Assim, decidimos avaliar essa questão em nosso âmbito, considerando como objetivos principais a avaliação da significância clínica das espécies e linhagens de ECN isoladas de processos infecciosos de recém-nascidos da unidade neonatal do Hospital das Clínicas da Faculdade de Medicina de Botucatu, UNESP.

\section{Materiais e métodos}

\section{Linhagens}

Neste estudo retrospectivo, foram estudadas 117 linhagens de ECN, isoladas de materiais clínicos provenientes de 107 recém-nascidos internados na unidade neonatal do Hospital das Clínicas da Faculdade de Medicina de Botucatu, no período de 1990 a 1996. Os procedimentos foram aprovados pelo Comitê de Ética em Pesquisa da Faculdade de Medicina.

\section{Critérios de inclusão}

Foram incluídas no estudo, linhagens de ECN isoladas de fluidos internos, incluindo sangue, urina e secreções, bem como de corpos estranhos, tais como cânulas, drenos e cateteres.

Nos casos de material biológico em que se encontrou uma microbiota normal, e os ECN estiveram em cultura associativa com outras bactérias, exigiu-se sempre sua nítida prevalência numérica.

\section{Critérios de exclusão}

Foram excluídas do estudo linhagens isoladas de recémnascidos, cujo registro de dados clínicos e laboratoriais referentes a um período de uma semana anterior e posterior ao isolamento de ECN não foi localizado.

\section{Identificação de estafilococos coagulase-negativa}

Os isolados, obtidos a partir de espécimes clínicos, foram semeados em ágar sangue e corados pelo método de Gram, objetivando-se sua pureza e a observação de sua morfologia e coloração específica. Após a confirmação dessas características, as linhagens foram submetidas às provas de catalase e coagulase. O gênero Staphylococcus 
foi diferenciado de Micrococcus, com base na prova de oxidação e fermentação da glicose ${ }^{16}$ e pela resistência à bacitracina $(0,04 \mathrm{U})$, indicada pela ausência de halo de inibição, ou formação de halo de até $9 \mathrm{~mm}$, e pela sensibilidade à furazolidona $(100 \mu \mathrm{g})$, caracterizada por halos de inibição de 15 a 35 mm de diâmetro ${ }^{17}$.

Para a identificação dos estafilococos coagulase-negativa, foram seguidos os critérios propostos por Kloos e Schleifer ${ }^{1}$, e Kloos e Bannerman ${ }^{3}$, conforme esquema simplificado de provas bioquímicas, o qual estabelece a realização de testes de utilização de açúcares: xilose, arabinose, sacarose, trealose, manitol, maltose, lactose, xylitol, ribose e frutose, bem como da caracterização de hemolisinas, redução de nitrato, urease, ornitina decarboxilase e de resistência à novobiocina.

\section{Relevância clínica}

Os dados clínicos que apoiaram a definição de significância clínica foram obtidos a partir da análise de prontuários dos pacientes. Foram valorizados os dados referentes a fatores perinatais de risco para infecção, como ruptura prolongada de membrana (> 24 horas); idade gestacional (IG); peso ao nascimento; procedimentos invasivos, como a cateterização arterial ou venosa umbilical, cateterização venosa central ou periférica, intubação endotraqueal (ventilação mecânica), procedimentos cirúrgicos, diálise peritoneal, nutrição parenteral, drenagem de tórax e derivação ventrículo-peritoneal. Além disso, foi considerado se houve ou não a remoção de corpo estranho durante o episódio de infecção por ECN.

Foi analisada a evolução clínica dos recém-nascidos na semana que antecedeu e na semana que sucedeu o isolamento do ECN, valorizando-se os diagnósticos e o quadro clínico sugestivo de infecção por ECN, que se caracteriza por sinais e sintomas incidiosos e inespecíficos, incluindo, mais frequientemente, o comprometimento do estado geral, a instabilidade térmica e a ocorrência de apnéias.

Associado à evolução clínica, foram valorizadas as alterações do hemograma e/ou positividade da proteína Creativa (PCR) por ocasião do isolamento do agente. Os parâmetros hematológicos normais foram os propostos por Manroe et al. ${ }^{18}$

Quanto aos óbitos, estes foram atribuídos à infecção por ECN quando ocorreram nas primeiras 72 horas do isolamento deste agente, e à possível associação a $\mathrm{ECN}$ se ocorrido entre quatro e sete dias após o isolamento de ECN.

Outro aspecto investigado e que auxiliou na consideração de relevância clínica foi o uso de antibioticoterapia prévia, antibióticos adequados para ECN após o resultado do diagnóstico bacteriológico, bem como o uso de antibióticos específicos, ou seja, a vancomicina, a oxacilina ou a teicoplanina. A determinação de antibioticoterapia adequada foi sempre baseada nos resultados do antibiograma arquivado nos prontuários ou realizado por ocasião do estudo.
As linhagens de ECN incluídas no estudo foram classificadas em significativas e contaminantes, conforme o critério do $\mathrm{CDC}^{19}$ modificado:

- significativas: linhagens isoladas de recém-nascidos que apresentaram três ou mais dos seguintes critérios: fatores de risco para infecção, quadro clínico, alteração hematológica e antibioticoterapia adequada. Também foram consideradas significativas as linhagens isoladas de pacientes que apresentaram apenas dois dos critérios e não receberam antibioticoterapia adequada, mas foram a óbito;

- contaminantes: linhagens isoladas de recém-nascidos que apresentaram somente fatores de risco para infecção e/ou apenas um dos demais critérios (quadro clínico ou alteração hematológica ou antibioticoterapia adequada). As linhagens isoladas de recém-nascidos que apresentaram três critérios, mas que tiveram evolução satisfatória do quadro infeccioso sem a administração de antibióticos adequados, também foram consideradas contaminantes. O isolamento de outro agente etiológico de fluidos internos e corpos estranhos, na mesma época do isolamento de ECN, também foi usado como critério para a classificação de contaminação.

\section{Análise estatística}

Os dados relativos à relevância clínica de linhagens de ECN foram analisadas pelo teste de qui-quadrado.

A prova não-paramétrica de Mann Whitney foi usada para análise do peso de nascimento e da idade dos recémnascidos.

Os dados que na análise univariada apresentaram um valor $\mathrm{de} \mathrm{p}<0,25$ foram posteriormente submetidos à análise multivariada, utilizando o modelo de regressão logística ${ }^{20}$, com a finalidade de avaliar simultaneamente a influência das diversas variáveis na incidência de infecção por ECN.

O nível de significância para todos os testes foi fixado em $\mathrm{p}<0,05^{21}$.

\section{Resultados \\ Linhagens}

Um total de 117 linhagens de ECN foram isoladas de diferentes materiais clínicos provenientes de 107 recémnascidos. A amostragem em referência constituiu-se de 60 isolados a partir de hemoculturas, 41 de corpos estranhos (30 de ponta de cateter, 10 de ponta de cânula, um de ponta de dreno torácico), 13 de secreções (dois de secreção de dreno, cinco de secreção gástrica, seis de secreção traqueal) e três de urina.

\section{Identificação de estafilococos coagulase-negativa}

Na Figura 1, acham-se expostos os resultados da distribuição das amostras de ECN isoladas, segundo a espécie. $\mathrm{O}$ 


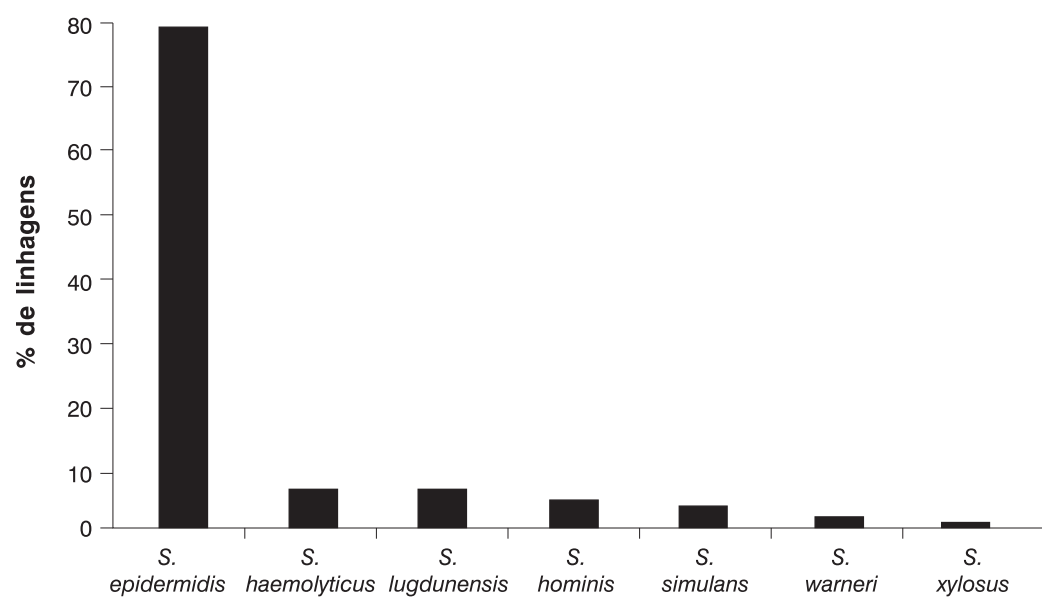

Figura 1 - Distribuição das espécies de ECN isoladas de recém-nascidos

S. epidermidis foi a espécie mais freqüentemente isolada, constituindo $77,8 \%$ da população estudada.

As Figuras 2 e 3 apresentam a distribuição das espécies de ECN classificadas como significativas e contaminantes, respectivamente. Das 117 linhagens incluídas no estudo, 60 $(51,3 \%)$ foram classificadas como clinicamente significativas, e $57(48,7 \%)$ como contaminantes.

Os resultados mostraram uma freqüência maior de $S$. epidermidis associado com infecção $(86,7 \%)$ do que com contaminação $(68,4 \%)(\mathrm{p}<0,05)$. A análise estatística da distribuição das outras espécies não mostrou diferença significativa.

Dos 54 recém-nascidos com infecção por $\mathrm{ECN}$, o $S$. epidermidis foi o agente etiológico isolado de 46 crianças $(85,2 \%)$. O S. haemolyticus foi responsável pelo quadro infeccioso apresentado por duas crianças $(3,7 \%)$, o $S$. lugdunensis por três $(5,6 \%)$, e o $S$. simulans $(1,8 \%)$, o $S$. warneri $(1,8 \%)$ e o $S$. xylosus $(1,8 \%)$ por um.

\section{Relevância clínica}

Dos 107 recém-nascidos, 54 foram considerados com infecção por ECN, e 53 sem infecção. Das 60 linhagens isoladas a partir de hemoculturas e analisadas quanto à significância clínica, 35 (58,3\%) foram interpretadas como significativas, e $25(41,7 \%)$ como contaminantes (Figuras 2 e 3). Das 41 linhagens isoladas de corpos estranhos, 21 $(51,2 \%)$ foram interpretadas como significativas, sendo 14 isoladas de ponta de catéter $(66,7 \%)$, seis de cânula $(28,6 \%)$ e uma de ponta de dreno torácico (4,7\%) (Figura 2). Das 13 linhagens isoladas de secreções, quatro $(30,8 \%)$ foram consideradas significativas, sendo uma de secreção de dreno torácico, e três de secreção traqueal. As linhagens interpretadas como clinicamente significativas foram isoladas em maior proporção a partir do sangue do que de secreções $(\mathrm{p}<0,05)$, porém sem diferença estatisticamente significativa quando comparado com corpo estranho. Por outro lado, as crianças classificadas como sem infecção apresentaram maior proporção de linhagens isoladas a partir de secreções do que de sangue $(\mathrm{p}<0,05)$.

A distribuição percentual das crianças classificadas com infecção e sem infecção por ECN conforme a idade gestacional, peso ao nascimento e dados pessoais encontrase na Tabela 1. Das 54 crianças com infecção por ECN, 43 $(79,6 \%)$ eram prematuras, sendo $18(33,3 \%)$ prematuras extremas (idade gestacional <31 semanas), comparado com $7(13,2 \%)$ no grupo de crianças sem infecção. Entretanto, esta diferença no número de pacientes abaixo de 31 semanas de idade gestacional entre os dois grupos não foi estatisticamente significativa (Tabela 1). Nesta tabela, observa-se que $27(50,0 \%)$ dos recém-nascidos com infecção por ECN apresentaram peso de nascimento $<1.500 \mathrm{~g}$, com diferença significativa do grupo dos recém-nascidos sem infecção (20,8\%). A mediana do peso ao nascimento também apresentou diferença estatisticamente significativa entre o grupo dos infectados por ECN (1.495g) e sem infecção $(2.270 \mathrm{~g})$. 


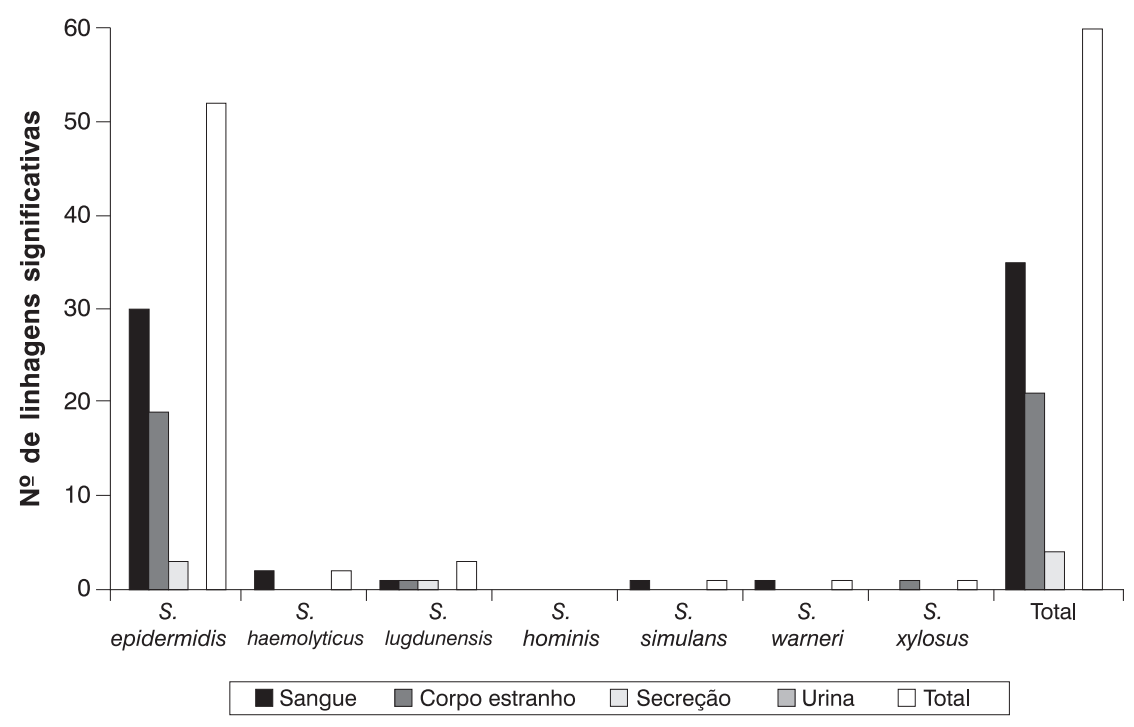

Figura 2 - Distribuição das espécies de ECN classificadas como clinicamente significativas, de acordo com o material clínico

A mediana da idade das crianças, por ocasião do isolamento de ECN, diferiu significantemente entre o grupo dos recém-nascidos com infecção (10 dias de vida) e crianças sem infecção (4 dias). Não houve diferença significativa quanto ao sexo e à procedência das crianças nos dois grupos.

A análise univariada dos dados clínicos dos pacientes, com relação aos fatores de risco perinatais para infecção, revelou diferença significativa entre o grupo das crianças com infeçcão e sem infecção, com respeito à internação em UTI, utilização de cateter, ventilação mecânica, nutrição parenteral, não remoção dos corpos estranhos e presença de dois ou mais corpos estranhos (Tabela 2).

Com referência aos dados hematológicos, foi observado uma maior proporção de recém-nascidos com neutrofilia

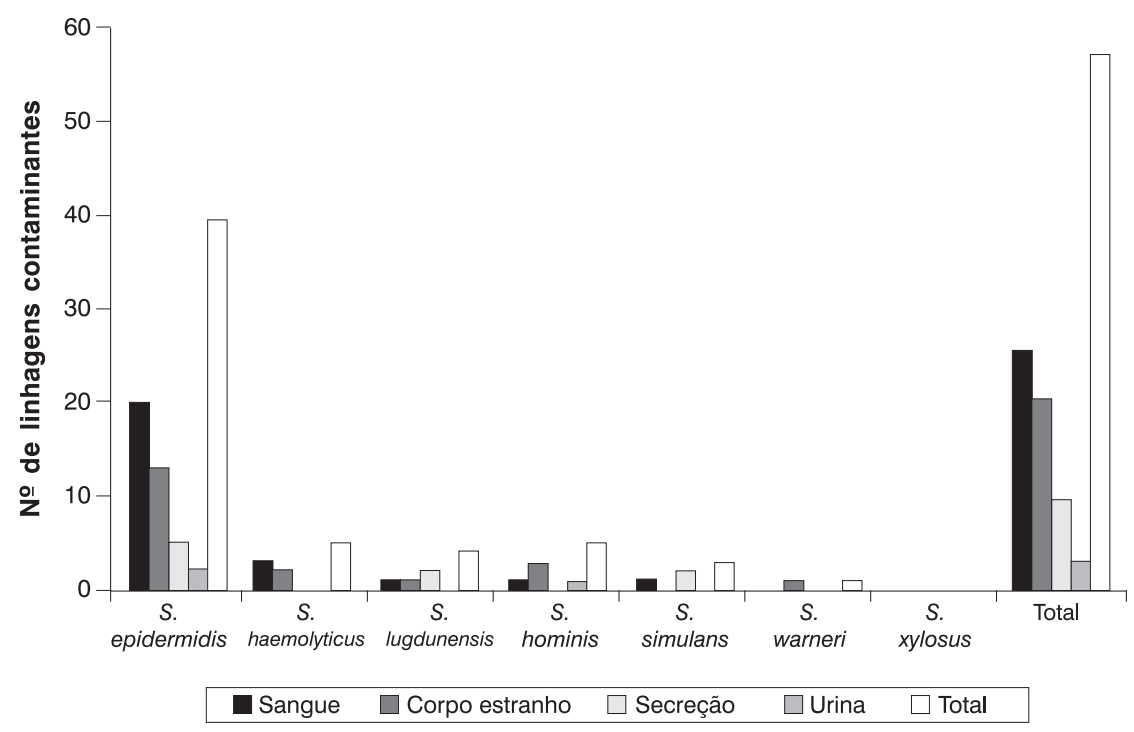

Figura 3 - Distribuição das espécies de ECN classificadas como contaminantes, de acordo com o material clínico 
Tabela 1 - Dados pessoais dos recém-nascidos

\begin{tabular}{lccccccc}
\hline Dados pessoais & \multicolumn{2}{c}{ Com infecção } & \multicolumn{2}{c}{ Sem infecção } & \multicolumn{2}{c}{ Total } & Valor de p \\
& N & $\mathbf{\%}$ & $\mathbf{N}$ & $\mathbf{\%}$ & $\mathbf{N}$ & $\mathbf{\%}$ & \\
\hline IG <31 & 18 & 33,3 & 7 & 13,2 & 25 & 23,4 & $\mathrm{~ns}$ \\
IG 31-36 & 21 & 38,9 & 26 & 49,0 & 47 & 43,9 & $\mathrm{~ns}$ \\
IG 37 & 4 & 7,4 & 3 & 5,7 & 7 & 6,5 & $\mathrm{~ns}$ \\
IG $\geq 38$ & 8 & 14,8 & 16 & 30,2 & 24 & 22,4 & $\mathrm{~ns}$ \\
PN < 1.500 g & 27 & 50,0 & 11 & 20,8 & 39 & 36,4 & 0,0002 \\
Mediana PN (g) & 1.495 & & 2.270 & & 1.985 & 0,0011 \\
Mediana idade (dias) & 10 & & 4 & & 7 & & 0,0042 \\
Sexo M & 24 & 44,4 & 27 & 50,9 & 51 & 47,7 & $\mathrm{~ns}$ \\
Nascido no HC/FMB & 34 & 62,9 & 31 & 58,5 & 65 & 60,7 & $\mathrm{~ns}$ \\
Total & 54 & 50,5 & 53 & 49,5 & 107 & 100 & \\
& & & & & & & \\
\hline
\end{tabular}

IG: idade gestacional (semanas). Obs: 4 recém-nascidos com idade gestacional desconhecida. ns: sem significância estatística ( $p>0,05)$, RN: recém-nascido, PN: peso ao nascimento, M: masculino, HC/FMB: Hospital das Clínicas da Faculdade de Medicina de Botucatu.

no grupo com infecção por ECN, quando comparados com o grupo sem infecção (Tabela 3).

A Tabela 4 apresenta os resultados da análise multivariada utilizando o modelo de regressão logística, apresentando como fatores de risco significativos na incidência de infeção por ECN, o muito baixo peso ao nascimento, a não remoção de corpo estranho e o uso de antibioticoterapia prévia. O cálculo do risco de ocorrência de infecção por ECN, sob a forma de razão de chances ou Odds Ratios, demonstrou que recém-nascidos com peso $<1.500 \mathrm{~g}$ ao nascer apresentaram um risco de 5,98 vezes maior de infecção por ECN em relação ao recém-nascido com peso superior, enquanto a não remoção de corpo estranho elevou o risco de infecção em 4,40 vezes. Mostrou também que a antibioticoterapia prévia aumentou a chance de incidência de infecção em 5,38 vezes.

Durante a hospitalização, foi verificado um percentual de $37 \%$ de óbito no grupo de crianças com infecção por ECN, comparado com 17,0\% no grupo dos recém-nascidos sem infecção. Entretanto, sete dos recém-nascidos que foram a óbito no primeiro grupo apresentaram infecção por gram-negativo, e quatro foram infectados com fungo, após

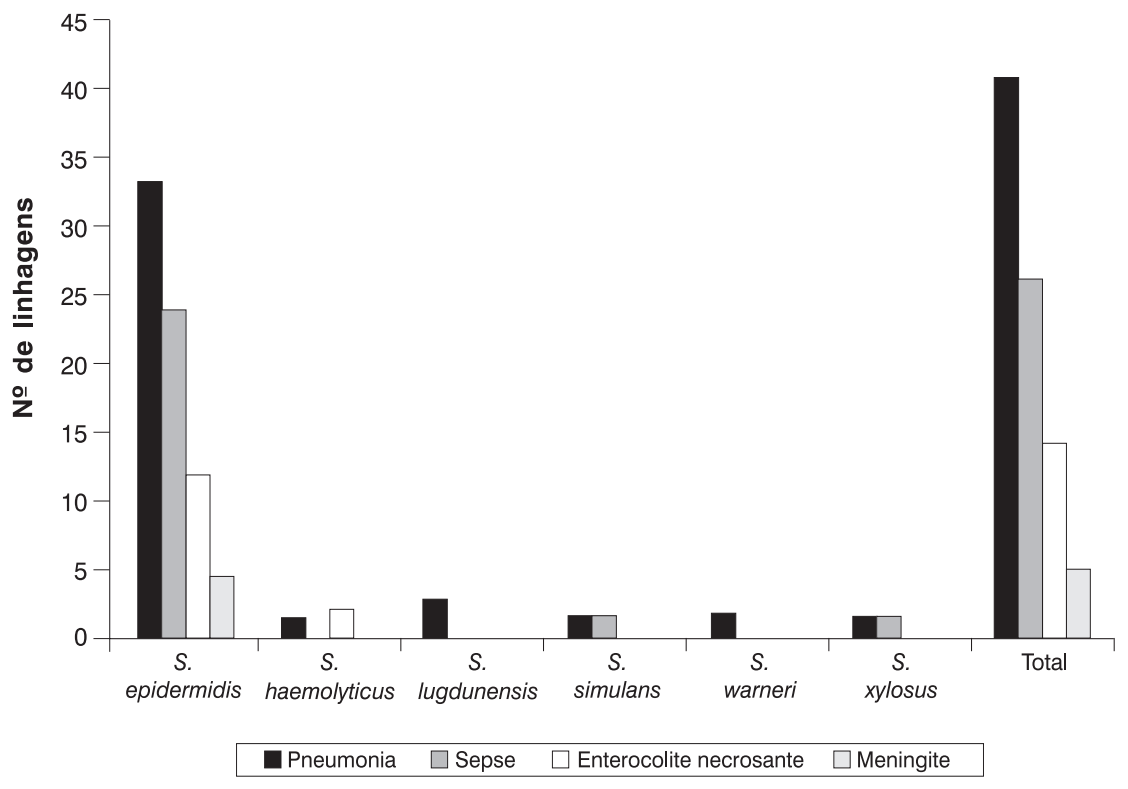

Figura 4 - Diagnóstico clínico dos recém-nascidos com infecção por ECN 
Tabela 2 - Fatores perinatais de risco para infecção por ECN

\begin{tabular}{|c|c|c|c|c|c|c|c|}
\hline \multirow[t]{2}{*}{ Fatores de risco } & \multicolumn{2}{|c|}{ Com infecção } & \multicolumn{2}{|c|}{ Sem infecção } & \multicolumn{2}{|c|}{ Total } & \multirow[t]{2}{*}{ Valor de $\mathrm{p}$} \\
\hline & $\mathbf{N}$ & $\%$ & $\mathbf{N}$ & $\%$ & $\mathbf{N}$ & $\%$ & \\
\hline Internação na UTI & 53 & 98,1 & 33 & 62,3 & 86 & 80,4 & $<0,0001$ \\
\hline Cateter & 48 & 88,9 & 33 & 62,3 & 81 & 75,7 & 0,0004 \\
\hline Complicação de cateter & 4 & 7,4 & 1 & 1,9 & 5 & 4,7 & ns \\
\hline Dreno & 10 & 18,5 & 5 & 9,4 & 15 & 14,0 & ns \\
\hline Ventilação mecânica & 33 & 61,1 & 18 & 34,0 & 51 & 47,7 & 0,0138 \\
\hline Nutrição parenteral & 35 & 64,8 & 22 & 41,5 & 57 & 53,3 & 0,0040 \\
\hline Derivação ventrículo-peritoneal & 3 & 5,5 & 2 & 3,8 & 5 & 4,7 & ns \\
\hline Não remoção dos corpos estranhos & 31 & 54,7 & 17 & 32,1 & 48 & 44,8 & 0,0010 \\
\hline Cirurgia & 9 & 16,7 & 6 & 11,3 & 15 & 14,0 & ns \\
\hline Diálise & 4 & 7,4 & 3 & 5,7 & 7 & 6,5 & ns \\
\hline Ruptura de membrana $>24$ horas & 18 & 33,3 & 17 & 32,1 & 35 & 32,7 & ns \\
\hline Dois ou mais corpos estranhos & 42 & 77,8 & 20 & 37,7 & 62 & 57,9 & 0,0001 \\
\hline Total RN & 54 & 50,5 & 53 & 49,5 & 107 & 100,0 & \\
\hline
\end{tabular}

RN: recém-nascido, ns: sem significância estatística $(p>0,05)$.

o episódio de infecção por ECN. Em adição, a mortalidade de dois recém-nascidos não foi associada com quadro infeccioso, e outros dois foram a óbito entre quatro a sete dias depois do isolamento de ECN. Sendo assim, os ECN contribuíram para a mortalidade de sete recém-nascidos $(13,0 \%)$. Desses sete recém-nascidos, cinco estavam submetidos a corpos estranhos infectados com ECN, que foram removidos na data do óbito, e quatro crianças eram prematuras extremas com peso $<1.000 \mathrm{~g}$.

A Figura 4 apresenta o diagnóstico clínico apresentado pelas crianças na semana que antecedeu e na semana que sucedeu o isolamento de ECN. Embora os 54 recémnascidos considerados com infecção por ECN tenham apresentado manifestações clínicas de sepse, a confirmação laboratorial foi observada em $26(48,1 \%)$ dos recém-nascidos. Foram verificados 41(75,9\%) episódios de infecção pulmonar confirmados radiologicamente, $14(25,0 \%)$ de manifestações clínicas e radiológicas de enterocolite necrosante (NEC), e $5(9,2 \%)$ de meningite. O S. epidermidis foi $o$ agente etiológico predominante nesses processos infecciosos. Em adição, o $S$. haemolyticus foi associado com um episódio de pneumonia e dois de NEC, enquanto o $S$. lugdunensis foi o agente de três episódios de pneumonia, o $S$. simulans de um caso de pneumonia e um de sepse, o $S$. warneri de um caso de pneumonia, e o $S$. xylosus associado com um episódio de pneumonia e um de sepse.

\section{Discussão}

Nossas observações em 117 linhagens indicaram o $S$. epidermidis como a espécie mais freqüentemente isolada $(77,8 \%)$, fato que corresponde ao relato de outros autores $^{5,8,22}$. De acordo com os dados de Oren e Merzbach ${ }^{10}$, a identificação de diferentes espécies de ECN nãoé clinica-

Tabela 3 - Dados laboratoriais dos recém-nascidos

\begin{tabular}{lccccccc}
\hline Dados laboratoriais & \multicolumn{2}{c}{ Com infecção } & \multicolumn{2}{c}{ Sem infecção } & \multicolumn{2}{c}{ Total } & \multirow{2}{*}{ Valor de p } \\
& $\mathbf{N}$ & $\mathbf{\%}$ & $\mathbf{N}$ & $\mathbf{\%}$ & $\mathbf{N}$ & $\mathbf{\%}$ & \\
\hline Leucocitose & 14 & 25,9 & 7 & 13,2 & 21 & 19,6 & $\mathrm{~ns}$ \\
Leucopenia & 12 & 22,2 & 6 & 11,3 & 18 & 16,8 & $\mathrm{~ns}$ \\
Neutrofilia & 24 & 44,4 & 9 & 17,0 & 33 & 30,8 & 0,0014 \\
Desvio à esquerda & 29 & 53,7 & 21 & 39,6 & 50 & 46,7 & $\mathrm{~ns}$ \\
Plaquetopenia & 4 & 7,4 & 2 & 3,8 & 6 & 5,6 & $\mathrm{~ns}$ \\
PCR positiva & 27 & 50,0 & 25 & 47,2 & 52 & 48,6 & $\mathrm{~ns}$ \\
Total RN & 54 & 50,5 & 53 & 49,5 & 107 & 100,0 & \\
\hline
\end{tabular}

PCR: proteína C-reativa, $R N$ : recém-nascido, ns: sem significância estatística $(p>0,05)$. 
Tabela 4 - Ajuste do modelo de regressão logística

\begin{tabular}{lcccc}
\hline Dados dos recém-nascidos & Valor de p & Odds Ratio & \multicolumn{2}{c}{$\begin{array}{c}\text { Intervalo } \\
\text { de confiança (95\%) } \\
\text { LI }\end{array}$} \\
\hline Prematuridade & & 0,323 & 8,620 \\
Peso < 1.500 g & 0,5409 & 1,669 & 1,579 & 22,727 \\
Internação na UTI & $0,0085^{*}$ & 5,988 & 0,843 & 166,66 \\
Cateter & 0,0666 & 12,04 & 0,276 & 16,854 \\
Complicação de cateter & 0,4630 & 2,159 & 0,138 & 333,33 \\
Ventilação mecânica & 0,3393 & 6,535 & 0,777 & 14,756 \\
Nutrição parenteral & 0,1044 & 3,386 & 0,248 & 8,752 \\
Não remoção de corpos estranhos & 0,6691 & 1,475 & 1,197 & 16,393 \\
Dois ou mais corpos estranhos & $0,0257^{*}$ & 4,405 & 0,506 & 58,823 \\
Leucocitose & 0,1612 & 5,524 & 0,333 & 8,182 \\
Leucopenia & 0,5396 & 1,650 & 0,389 & 10,526 \\
Neutrofilia & 0,4019 & 2,020 & 0,904 & 12,987 \\
Desvio à esquerda & 0,0700 & 3,412 & 0,513 & 7,246 \\
Antibioticoterapia prévia & 0,3316 & 1,926 & 1,508 & 19,230 \\
\hline
\end{tabular}

RN: recém-nascido * Significativo ao nível de $5 \%$ de significância.

mente significante. Entretanto, nossos resultados revelaram que as linhagens de $S$. epidermidis isoladas foram significativamente mais associadas com infecção $(86,7 \%)$ do que com contaminação $(68,4 \%)$. Silbert et al. ${ }^{23}$, em estudo para determinar a prevalência de infecção versus contaminação em pacientes com menos de 60 dias de vida, com hemoculturas positivas para ECN, encontrou $91,1 \%$ dos isolados pertencentes à espécie S. epidermidis, $3(6,7 \%)$ à $S$. hominis e $1(2,2 \%)$ à $S$. warneri, sendo que no grupo de pacientes infectados, somente $S$. epidermidis foi encontrado. Esses resultados confirmam os achados de Lowy e Hammer ${ }^{11}$, que acreditam na importância da identificação das espécies de ECN para diferenciação entre contaminação e infecção.

Embora o S. epidermidis seja a espécie mais caracterizada e envolvida etiologicamente, outras espécies de ECN patogênicas têm sido isoladas de uma variedade de fontes clínicas $^{2}$. Em nosso estudo, outras espécies foram associadas com infecção, incluindo-se S. haemolyticus, S. lugdunensis, $S$. simulans, $S$. warneri e $S$. xylosus. Hall et al. ${ }^{8}$ também isolaram linhagens de $S$. haemolyticus e S. simulans de crianças com evidência clínica e laboratorial de sepse, bem como de pneumonia.

Em nosso estudo, dos 54 recém-nascidos com infecção por ECN, a maioria $(79,6 \%)$ era de prematuros, com $33,3 \%$ deles apresentando prematuridade extrema (IG < 31 semanas), e $50,0 \%$ com peso ao nascimento $<1.500 \mathrm{~g}$, com mediana do peso igual a $1.495 \mathrm{~g}$. Do ponto de vista comparativo, resultados similares têm sido obtidos por outros investigadores ${ }^{4,8,24}$.

Vários são os fatores que contribuem para que o prematuro, especialmente o de muito baixo peso, seja mais susce- tível à infecção. Colabora para a maior gravidade dos quadros infecciosos, a imaturidade do sistema imunológico, que se traduz na deficiência da fagocitose, opsonização por anticorpos e funções do complemento 25 .

A mediana da idade dos 54 recém-nascidos com infecção por ECN foi de 10 dias, diferindo significativamente do grupo sem infecção (quatro dias). Esses dados denotam a característica peculiar desses microrganismos, ou seja, seu envolvimento, na maioria das vezes, na etiologia de quadros clínicos tardios de infecção hospitalar. Somente duas $(4,4 \%)$ das crianças com infecção por ECN apresentaram idade inferior a dois dias de vida, e destas, uma apresentou ruptura de membrana > que 24 horas, como fator de risco. Resultados similares foram obtidos por Hensey et al. ${ }^{26}$, que relataram a ocorrência de somente $12 \%$ das infecções por ECN nas primeiras 48 horas de vida, enquanto todas as infecções por Streptococcus do Grupo B, Streptococcus viridans e Haemophilus influenzae ocorreram nesse período e associadas com a rotura prolongada de membrana.

Dentre os fatores de risco para infecção, o uso de cateter foi significativamente mais freqüente nos recém-nascidos com infecção por ECN, e esse achado é concordante com os dados de outros pesquisadores que alertam para a importância desse procedimento ${ }^{27}$. Os cateteres vasculares são fontes de infecção, por serem facilmente colonizados por microrganismos da pele presentes ao longo do local de inserção, especialmente pelos ECN, que são os microrganismos prevalentes como flora normal da pele e mucosas.

No presente estudo, o uso de nutrição parenteral foi mais freqüente nos recém-nascidos com infecção. A importância da nutrição parenteral como fator de risco decorre não só da necessidade de utilização de cateteres vasculares 
e da manipulação dos mesmos, mas também de sua composição. A administração de nutrição parenteral, e especialmente de lipídeos, através desses cateteres, pode servir como um meio de cultura que favorece rápida proliferação bacteriana ${ }^{4}$.

A frequiência da intubação orotraqueal também foi significativamente maior no grupo dos recém-nascidos com infecção por ECN, semelhante ao observado por Stoll et al. ${ }^{24} \mathrm{~A}$ presença da cânula na traquéia atua como corpo estranho, comprometendo a integridade das barreiras mucosas e propiciando a colonização por microrganismos.

Adicionalmente, a presença de dois ou mais corpos estranhos e sua não remoção foi significativamente mais elevada nos recém-nascidos com infecção, fato que vários autores têm alertado, e ressaltado a importância de sua rápida remoção, além da terapia com antimicrobianos ${ }^{28}$. Essa condição, quando não controlada, pode ser agravada pela produção de um exopolissacarídeo por alguns ECN associados ao processo infeccioso, que favorece a permanência desses microrganismos no corpo estranho pela interferência com a resposta imune do hospedeiro e redução da atividade de antimicrobianos ${ }^{28}$. Nesse sentido, nosso estudo confirma essa observação pelo fato de que três recémnascidos com corpos estranhos colonizados com ECN foram a óbito, apesar da antibioticoterapia adequada.

$\mathrm{Na}$ avaliação do hemograma, foi observada uma freqüência significativamente maior de neutrofilia no grupo de crianças com infecção, quando comparado com o grupo dos recém-nascidos sem infecção. A proteína C-reativa ( $\mathrm{PCR}$ ) tem sido útil no diagnóstico e no acompanhamento da resposta à terapêutica dessas infecções. Em nosso estudo, não houve diferença significativa entre os recém-nascidos com infecção e os sem infecção. Essa condição pode ser explicada pelo fato de que o grupo de crianças sem infecção incluiu vários recém-nascidos com infecção por outros microrganismos que não os ECN.

Resultados obtidos por Schmidt et al. ${ }^{29}$ mostraram que $64 \%$ das crianças com infecção por ECN apresentaram PCR positiva, e apenas $20 \%$ e $8 \%$ das crianças apresentaram a proteína nos grupos dos suspeitos e controle (sem infecção), respectivamente. Entretanto, $88 \%$ das crianças com sepse por outros patógenos também apresentaram resultado positivo.

Outro achado coerente com os dados da literatura ${ }^{27}$ foi o uso de antibioticoterapia prévia nos recém-nascidos com infecção por ECN. O uso prévio de antibióticos pode suprimir a flora normal e selecionar microrganismos resistentes, aumentando não apenas o risco de infecção, mas também sua gravidade e a dificuldade de seu tratamento.

Os resultados obtidos na análise de regressão logística apontaram como fatores significativamente predisponentes para a infecção por ECN o peso de nascimento $<1.500 \mathrm{~g}$ $(\mathrm{OR}=5,98)$, a não remoção de corpo estranho $(\mathrm{OR}=4,40)$, e a antibioticoterapia prévia $(\mathrm{OR}=5,38)$, indicando um risco 4 a 5 vezes maior para a incidência de infecção por $\mathrm{ECN}$, e a importância da valorização desses germes como agentes etiológicos significativos quando isolados de $\mathrm{RN}$ nessas condições.

A mortalidade dos recém-nascidos classificados com infecção por ECN em nosso estudo foi de $37,0 \%$, e os ECN estiveram associados ao óbito de 13,0\% dos recém-nascidos; em 3,7\% houve possível associação com a infecção causada por ECN. A mortalidade associada a ECN aqui evidenciada é semelhante à encontrada por outros pesquisadores (7 a 14,3\%) em países desenvolvidos ${ }^{8}$. A mortalidade durante a hospitalização $(37,0 \%)$ foi elevada, porém compatível com a casuística estudada e com as cifras relatadas por outros autores ${ }^{30}$. Vários fatores interferem na mortalidade, alguns inerentes à população, como a limitada resposta imune do prematuro de baixo peso, que pode ser agravada por uma patologia prévia associada às dificuldades no diagnóstico precoce de infecção e à não remoção de corpos estranhos colonizados com esses microrganismos.

Nossos resultados mostraram uma freqüência de 26 episódios de sepse laboratorialmente confirmada, sendo que, em $15(51,7 \%)$ desses episódios, os recém-nascidos tinham cateter ou cânula colonizados com esses microrganismos. Resultados similares foram verificados por Noel e Edelson $^{31}$ na UTI neonatal do Hospital de Nova Iorque, onde foi constatado que em 23 episódios envolvendo 38 pacientes, $57 \%$ destes ocorreram em crianças com cateteres vasculares contaminados ou suspeitos de contaminação.

A ocorrência de sepse associada a enterocolite necrosante (NEC) causada por ECN também tem sido descrita ${ }^{31}$, e demonstra que esses microrganismos podem inicialmente colonizar o trato gastrintestinal através da intubação endotraqueal ou nasogástrica, e secundariamente causar sepse quando a integridade da barreira intestinal é comprometida pela isquemia ${ }^{24}$. Das 54 crianças com infecção por ECN, 14 $(25,9 \%)$ apresentaram episódios de NEC, sendo seis $(42,8 \%)$ desses, associados com sepse laboratorialmente confirmada. Em adição, quatro desses recém-nascidos com NEC e sepse estavam submetidos ao uso de cateter ou cânula, semelhante aos resultados relatados por Noel e Edelson ${ }^{31}$.

Nossos resultados mostraram uma frequiência de 75,9\% de infecções pulmonares associadas com ECN, superior à observada por outros autores ${ }^{8}$. Essa diferença pode ser devida a fatores próprios dos recém-nascidos prematuros que os predispõem às infecções pulmonares, freqüentemente por problemas respiratórios que prejudicam a oxigenação e trocas gasosas e pelo uso de ventilação mecânica, que lesa o órgão, tornando-o mais suscetível à infecção ${ }^{24}$. O S. epidermidis foi o agente etiológico associado com $82,9 \%$ dos episódios de pneumonia constatados, dados esses semelhantes aos encontrados por Hall et al. ${ }^{8}$

Em nosso estudo, das 117 linhagens de ECN isoladas, 60 foram consideradas de significância clínica, incluindo 35 isoladas a partir de hemoculturas, 21 de corpos estranhos e quatro de secreções, revelando diferença estatística em relação ao material biológico de origem, com uma maior frequência de linhagens clinicamente significativas isoladas de hemoculturas e de contaminantes isolados de secre- 
ções. Entretanto, para as linhagens isoladas de corpo estranho, não foi verificada diferença estatisticamente significante.

Esses resultados demonstram que os ECN são importantes patógenos nosocomiais, e, portanto, quando do seu isolamento a partir de sangue e corpos estranhos de recémnascidos prematuros de muito baixo peso $(<1.500 \mathrm{~g})$, não devem ser ignorados, e sim classificados como contaminantes, havendo a necessidade de um exame criterioso dos dados clínicos e laboratoriais do paciente para determinar a relevância clínica das linhagens isoladas.

\section{Referências bibliográficas}

1. Kloos WE, Schleifer KH. Simplified scheme for routine identification of human Staphylococcus species. J Clin Microbio 1975;1:82-8.

2. Kloos WE, Bannerman TL. Update on clinical significance of coagulase-negative staphylococci. Clin Microbiol Rev 1994;7:117-40.

3. Kloos WE, Bannerman TL. Staphylococcus and Micrococcus. In: Murray PR, Baron EJ, Pfaller MA, Tenover FC, Yolken RH, editores. Manual of Clinical Microbiology. $6^{\mathrm{a}}$ ed. Washington: American Society Microbiology; 1999. p.264-82.

4. Freeman J, Platt R, Epstein MF, Smith NE, Sidebottom DG, Goldmann DA. Birth weight and length of stay as determinants of nosocomial coagulase-negative staphylococcal bacteremia in neonatal intensive care unit populations: potential for confounding. Am J Epidemiol 1990;132:1130-40.

5. Hudome SM, Fisher MC. Nosocomial infections in the neonatal intensive care. Curr Opin Infect Dis 2001;14:303-7.

6. Kacica MA, Horgan MJ, Ochoa L, Sandler R, Lepow ML, Venezia R. Prevention of gram-positive sepsis in neonates weighting less than 1500 grams. J Pediatr 1994;125:253-8.

7. Ho JJ. Late onset infection in very low birth weight infants in Malaysian Level 3 neonatal nurseries. Pediatr Infect Dis J 2001; 20:557-60.

8. Hall RT, Hall SL, Barnes WG, Izuegbu J, Rogolsky M, Zorbas I. Characteristics of coagulase-negative staphylococci from infants with bacteremia. Pediatr Infect Dis J 1987;6:377-83.

9. Kleeman KT, Bannerman TL, Kloos WE. Species distribution of coagulase-negative staphylococcal isolates at a community hospital and implications for selection of staphylococcal identification procedures. J Clin Microbiol 1993;31:1318-21.

10. Oren I, Merzbach D. Clinical and epidemiological significance of species identification of coagulase-negative staphylococci in a microbiological laboratory. Isr J Med Sci 1990;26:125-8.

11. Lowy FD, Hammer SM. Staphylococcus epidermidis infections. Ann Intern Med 1983;99:834-9.

12. Archer GL. Staphylococcus epidermidis and other coagulasenegative staphylococci. In: Mandell GL, Bennett JE, Dolin R, editores. Mandell, Douglas and Bennett's principles and practice of infectious diseases. $4^{\mathrm{a}}$ ed. New York: Churchill-Livingstone; 1995. p.1777-84.

13 Herchline TE, Ayers LW. Ocurrence of Staphylococcus lugdunensis in consecutive clinical cultures and relationship of isolation. J Clin Microbiol 1991;29:419-2.

14. Lambe Jr. DW, Ferguson KP, Keplinger JL, Gemmell CG, Kalbfleisch JH. Pathogenicity of Staphylococcus lugdunensis, Staphylococcus schleiferi, and three other coagulase-negative staphylococci in a mouse model and possible virulence factors. Can J Microbiol 1990;36:455-63.
15. Low DE, Schmidt BK, Kirpalani HM, Moodie R, Kreiswirth B, Matlow A, et al. An endemic strain of Staphylococcus haemolyticus colonizing and causing bacteremia in neonatal intensive care unit patients. Pediatrics 1992;89:696-700.

16. Evans JB, Bradford Junior WL, Niven Junior CF. Comments concerning the taxonomy of the genera micrococcus and staphylococcus. Int Bull Bacteriol Nomencl Taxon 1955;5:61-6.

17. Baker JS. Comparison of various methods for differentiation of staphylococci and micrococci. J Clin Microbiol 1984;19:875-9.

18. Manroe BL, Weinberg AG, Rosenfeld CR, Browne R. The neonatal blood count in health and disease. I. Reference values for neutrophilic cells. J Pediatr 1979;95:89-98.

19. Garner JS, Jarvis WR, Emori TG, Horan TC, Hughes JM. CDC definitions for nosocomial infections. In: Olmsted RN, editor. APIC infection control and applied epidemiology: principles and practice. St. Louis: Mosby; 1996. p. A1-A20.

20. Collett D. Modelling binary data. London: Chapman and Hall; 1991.

21. Curi PR. Metodologia e análise da pesquisa em Ciências Biológicas. $1^{\mathrm{a}}$ ed. Botucatu: Tipomic; 1997.

22. Neumeister B, Kastner S, Conrad S, Klotz G, Bartmann P. Characterization of coagulase-negative staphylococci causing nosocomial infections in preterm infants. Eur J Clin Microbiol Infect Dis 1995; 14:856-63.

23. Silbert S, Rosa DD, Matte U, Goldim JR, Barcellos SH, Procianoy RS. Staphylococcus sp. Coagulase-negativa em hemoculturas de pacientes com menos de sessenta dias de idade: infecção versus contaminação. J Pediatr (Rio J) 1997;73:161-5.

24. Stoll BJ, Gordon T, Korones SB, Shankaran S, Tyson J, Bauer CR, et al. Late-onset sepsis in very low birthweight neonates: a report from the National Institute of Child Health and Human Development Neonatal Research network. J Pediatr 1996;129:63-71.

25. Eshali H, Ringertz S, Nystrom S, Faxelius G. Septicaemia with coagulase negative staphylococci in a neonatal intensive care unit. Acta Paediatr Scand Suppl 1989;360:127-34.

26. Hensey OJ, Hart CA, Cooke RWI. Serious infection in a neonatal intensive care unit: a two-year survey. J Hyg Camb 1985;95:289-97.

27. Nichols RL, Raad II. Management of bacterial complications in critically ill patients: surgical wound and catheter-related infections. Diagn Microbiol Infect Dis 1999;33:121-30.

28. Gray ED, Peters G, Verstegen M, Regelmann WE. Effect of extracellular slime substance from Staphylococcus epidermidis on the human cellular immune response. Lancet 1984;1:365-7.

29. Schmidt BK, Kirpalani HM, Corey M, Low DE, Philip AGS, Ford-Jones EL. Coagulase-negative staphylococci as true pathogens in newborn infants: a cohort study. Pediatr Infect Dis J 1987;6: 1026-31.

30. Stoll BJ. The global impact of neonatal infection. Clin Perinatol 1997;24:1-21.

31. Noel GJ, Edelson PJ. Staphylococcus epidermidis bacteremia in neonates: further observations and the occurrence of focal infection. Pediatrics 1984;74:832-7.

Endereço para correspondência:

Dra. Maria de Lourdes Ribeiro de Souza da Cunha

Dep. de Microbiologia e Imunologia -

Instituto de Biociências - UNESP - Rubião Júnior

Botucatu, SP- Caixa Postal 510 - CEP 18618-000

Fone: (14) 6802.6058 - Fax: (14) 6821.3744

E-mail: cunhamlr@ibb.unesp.br 